\title{
Exacerbation of Inflammation-associated Colonic Injury in Rat through Inhibition of Cyclooxygenase-2
}

\author{
Brian K. Reuter, ${ }^{\star}$ Samuel Asfaha, ${ }^{\star}$ André Buret, ${ }^{\ddagger}$ Keith A. Sharkey, ${ }^{\S}$ and John L. Wallace* \\ ${ }^{*}$ Department of Pharmacology and Therapeutics, ${ }^{\ddagger}$ Department of Biological Sciences, and ${ }^{\S}$ Department of Physiology and Biophysics, \\ University of Calgary, Calgary, Alberta, T2N 4N1, Canada
}

\begin{abstract}
Cyclooxygenase type 1 is constitutively expressed and accounts for synthesis of prostaglandins in the normal gastrointestinal tract. Cyclooxygenase- 2 is expressed at sites of inflammation. Selective inhibitors of cyclooxygenase- 2 have been suggested to spare gastrointestinal prostaglandin synthesis, and therefore lack the ulcerogenic effects associated with standard nonsteroidal antiinflammatory drugs. However, the effects of cyclooxygenase- 2 inhibitors on inflamed gastrointestinal mucosa have not been examined. We examined cyclooxygenase- 2 mRNA and protein expression before and after induction of colitis in the rat, the contribution of cyclooxygenase- 2 to colonic prostaglandin synthesis during colitis and the effects of selective inhibitors of cyclooxygenase- 2 on colonic injury in this model. Cyclooxygenase- 2 mRNA expression increased three to sixfold during the period $24 \mathrm{~h}$ to $1 \mathrm{wk}$ after induction of colitis, with marked increases in cyclooxygenase- 2 protein expression in the lamina propria and muscularis of the colon during colitis. Cyclooxygenase-1 expression (mRNA and protein) was not affected by the induction of colitis. The prostaglandins produced during colitis were largely derived from cyclooxygenase-2. Treatment with selective cyclooxygenase- 2 inhibitors resulted in exacerbation of colitis, with perforation occurring when the compounds were administered for a week. These studies demonstrate that suppression of cyclooxygenase- 2 can result in exacerbation of inflammation-associated colonic injury. (J. Clin. Invest. 1996. 98:2076-2085.) Key words: prostaglandins • inflammatory bowel disease • nonsteroidal antiinflammatory drug $\bullet$ ulcer $\bullet$ mucosal defense
\end{abstract}

\section{Introduction}

The ability of nonsteroidal antiinflammatory drugs (NSAIDs) ${ }^{1}$ to cause gastroduodenal ulceration and to promote the bleed-

Address correspondence to John L. Wallace, Department of Pharmacology and Therapeutics, University of Calgary, 3330 Hospital Drive NW, Calgary, Alberta, T2N 4N1 Canada. Phone: 403-220-4539; FAX: 403-270-3353; E-mail: wallacej@acs.ucalgary.ca

Received for publication 3 July 1996 and accepted in revised form 27 August 1996.

1. Abbreviations used in this paper: COX, cyclooxygenase; GAPDH, glyceraldehyde 3-phosphate dehydrogenase; IBD, inflammatory bowel disease; MPO, myeloperoxidase; NSAID, nonsteroidal antiinflammatory drug; RT-PCR, reverse transcriptase PCR; TNBS, trinitrobenzene sulfonic acid.

J. Clin. Invest.

(C) The American Society for Clinical Investigation, Inc. 0021-9738/96/11/2076/10 \$2.00

Volume 98, Number 9, November 1996, 2076-2085 ing of preexisting ulcers is well established (1). At least in the case of gastric ulceration, there is very convincing evidence that this action of NSAIDs is directly linked to their ability to suppress prostaglandin synthesis, by inhibiting the activity of the enzyme cyclooxygenase (COX). The discovery of two distinct isoforms of $\mathrm{COX}$, one of which is constitutively expressed in the gastrointestinal tract (COX-1) and one that is induced at sites of inflammation (COX-2), has led to the proposal that selective inhibitors of COX-2 will spare gastrointestinal prostaglandin synthesis, and therefore also spare the gastrointestinal tract of damage (2-7). As these compounds would inhibit prostaglandin synthesis at sites of inflammation, they would be effective as antiinflammatory drugs (2-7). The vast majority of NSAIDs presently marketed show greater selectivity for COX-1 than COX-2 $(3,4)$. Thus, at concentrations that are required to inhibit prostaglandin synthesis at sites of inflammation (i.e., COX-2 activity), marked suppression of prostaglandin synthesis in the gastrointestinal tract (i.e., COX-1) occurs.

There are now considerable data from experimental models supporting the concept that selective COX-2 inhibitors spare the gastrointestinal tract. These agents have been shown to be effective in reducing inflammation and pain while causing significantly less gastrointestinal damage than standard NSAIDs (6-8). Moreover, some NSAIDs (e.g., nabumetone and etodolac) that have been introduced over the past decade and have been shown to produce lower rates of gastrointestinal ulceration than more established NSAIDs $(9,10)$ have subsequently been shown to exert some degree of selectivity for COX-2 over COX-1 $(2,11)$. Whether or not this selectivity for COX-2 accounts for the lower ulcerogenicity of these compounds has not yet been established.

Despite the evidence supporting the hypothesis that selective COX-2 inhibitors will be gastrointestinal sparing, there remains a concern that, in situations in which the mucosa is inflamed, COX-2 is likely to be expressed and might be responsible for producing the prostaglandins that contribute to ulcer healing and downregulation of the inflammatory response. Ulcers in the gastrointestinal tract, including those associated with Helicobacter pylori infection and inflammatory bowel disease (IBD), are associated with mucosal inflammation. NSAIDs can delay peptic ulcer healing and can exacerbate $\operatorname{IBD}(1,12,13)$. It is possible that these effects of NSAIDs are attributable to suppression of the production of prostaglandins from COX-2. If so, selective COX-2 inhibitors might exert detrimental effects in circumstances in which the gastrointestinal mucosa is inflamed. The extent to which COX-2 contributes to colonic prostaglandin synthesis in IBD or in experimental models of colitis has not yet been reported.

We have previously used a rat model of colitis to examine the mechanism underlying the exacerbation of IBD by NSAIDs (14). In these animals, NSAIDs were found to significantly increase colonic damage, in many cases leading to perforation of the colon and death. The exacerbation of colitis ap- 
peared to be related to the ability of the NSAIDs to suppress colonic prostaglandin synthesis (14). In the present study, we have used this model to determine if COX-2 expression (protein and mRNA) is altered in the inflamed colon, to determine the contribution of COX-2 to colonic prostaglandin synthesis before and after induction of colitis, and to determine if selective inhibitors of COX-2 would cause exacerbation of inflammation-associated colonic injury, as is seen with standard NSAIDs.

\section{Methods}

Animals. Male Wistar rats weighing 200-225 g were obtained from Charles River Breeding Farms, Ltd. (Montreal, QC, Canada) and were housed in plastic cages. The rats had free access to water and standard pelleted laboratory chow throughout the study. All experimental protocols described in this report were approved by the Animal Care Committee of the University of Calgary in accordance with the guidelines of the Canadian Council on Animal Care.

Induction of colitis and treatment protocol. Colitis was induced by intracolonic instillation of the hapten trinitrobenzene sulfonic acid (TNBS, $60 \mathrm{mg} / \mathrm{ml})$ in a vehicle of $50 \%$ ethanol $(0.5 \mathrm{ml})$, as described in detail previously $(14,15)$.

The rats were treated orally, beginning $3 \mathrm{~h}$ before induction of colitis and continuing every $12 \mathrm{~h}$ thereafter for up to $7 \mathrm{~d}$, with one of the following drugs suspended in a vehicle of $0.5 \%$ carboxymethylcellose (or the vehicle alone): diclofenac $(10 \mathrm{mg} / \mathrm{kg})$, naproxen $(5 \mathrm{mg} / \mathrm{kg})$, nabumetone ( 25 or $75 \mathrm{mg} / \mathrm{kg}$ ), etodolac (10 or $50 \mathrm{mg} / \mathrm{kg}$ ), or L745,337 ( 1 or $5 \mathrm{mg} / \mathrm{kg}$ ). Diclofenac, naproxen, and aspirin are commonly used NSAIDs that inhibit both COX-1 and COX-2 $(3,4,11)$. Nabumetone and etodolac are moderately selective inhibitors of COX-2 over COX-1 (7 and 10 times, respectively) (3,11). L745,337 is a highly selective inhibitor of COX-2, being $\sim 400 \times$ more active on this isoform than on COX-1 (7). The doses of each test drug used were selected because they have been shown to exert significant antiinflammatory effects in the carrageenan-induced paw edema model $(7,16,17)$. At the dose used, diclofenac has been shown to cause small intestinal damage in the rat (18), but the other test drugs do not cause signifi- cant small intestinal injury $(16,19)$. Each treatment group consisted of at least 10 rats, with the exception of the group treated with the 1 $\mathrm{mg} / \mathrm{kg}$ dose of L745,337, which consisted of 5 rats.

Rats were monitored at least twice a day throughout the 7-d dosing period and for a further $7 \mathrm{~d}$ thereafter. When deaths occurred, necropsy was performed as soon afterwards as possible. Rats that survived until the end of the study period were killed and the distal $10 \mathrm{~cm}$ of colon was removed and pinned out on a wax block for assessment of the severity of damage, as described previously (20). The presence or absence of diarrhea and adhesion between the colon and other organs were noted, and the severity of colonic ulceration was scored using the criteria outlined in Table I. The maximum thickness of the wall of the distal colon (in millimeters) was measured using calipers. A global colonic damage score was calculated that included the score of ulceration, maximal wall thickness, and the presence of diarrhea and adhesions.

A separate series of studies was performed to determine the ability of a number of test drugs to influence the severity of colonic damage and granulocyte infiltration, as measured by tissue myeloperoxidase (MPO) activity. Groups of five rats each were treated orally with vehicle, diclofenac $(10 \mathrm{mg} / \mathrm{kg}), \mathrm{L} 745,337(5 \mathrm{mg} / \mathrm{kg})$, or nabumetone $(75 \mathrm{mg} / \mathrm{kg}) 3 \mathrm{~h}$ before receiving TNBS intracolonically. The drugs were given thereafter at $12 \mathrm{~h}$ intervals for $3 \mathrm{~d}$ (i.e., total of seven doses of the drugs were given), and the rats were killed $12 \mathrm{~h}$ after the final dose. A blood sample was drawn from a tail vein for determination of hematocrit. The rat was then killed by cervical dislocation, the colon was excised, and the severity of colonic damage was scored, as described above, by an observer unaware of the treatment the rats had received. A sample $(\sim 200 \mathrm{mg})$ of distal colon was excised and immediately frozen on dry ice for subsequent measurement of MPO activity (20). The remaining tissue was fixed in neutral buffered formalin. A 1-cm section of colon from each rat was processed by routine techniques for light microscopy. The slides were coded to avoid observer bias. The percentage of each section exhibiting ulceration was then determined.

Eicosanoid measurement. Groups of five rats each were given TNBS, as described above, to induce colitis. $72 \mathrm{~h}$ later, the rats were orally treated with vehicle, diclofenac $(10 \mathrm{mg} / \mathrm{kg}$ ) or L745,337 (1 or $5 \mathrm{mg} / \mathrm{kg}$ ). $2 \mathrm{~h}$ later, the rats were anesthetized with sodium pentobar-

Table I. Criteria for Macroscopic Scoring of Colonic Damage

\begin{tabular}{|c|c|}
\hline Feature & Score \\
\hline \multicolumn{2}{|l|}{ Ulceration } \\
\hline Normal appearance. & 0 \\
\hline Focal hyperemia, no ulcers. & 1 \\
\hline Ulceration without hyperemia or bowel wall thickening. & 2 \\
\hline Ulceration with inflammation at one site. & 3 \\
\hline Ulceration/inflammation at two or more sites. & 4 \\
\hline Major sites of damage extending $>1 \mathrm{~cm}$ along the length of the colon. & 5 \\
\hline $\begin{array}{l}\text { When an area of damage extended }>2 \mathrm{~cm} \text { along the length of the colon, the score is in } \\
\text { each additional centimeter of involvement. }\end{array}$ & $\begin{array}{l}6-10 \\
\text { plus }\end{array}$ \\
\hline \multicolumn{2}{|l|}{ Adhesions } \\
\hline No adhesions. & 0 \\
\hline Minor adhesions (colon can be separated from other tissue with little effort). & 1 \\
\hline Major adhesions. & 2 \\
\hline \multicolumn{2}{|l|}{ Diarrhea } \\
\hline No & 0 \\
\hline Yes & 1 \\
\hline \multicolumn{2}{|l|}{ Thickness } \\
\hline The maximal bowel wall thickness $(x)$, in millimeters, was added to the above score. & $\begin{array}{c}x \\
\text { Total score }\end{array}$ \\
\hline
\end{tabular}


bital (60 mg/kg i.p.) and in vivo colonic dialysis was performed, as described previously (20). $1 \mathrm{~h}$ after inserting a dialysis tube intrarectally and instilling $1 \mathrm{ml}$ of dialysis buffer, the tube was withdrawn and the dialysate transferred to an Eppendorf tube. Volume was measured gravimetrically and the sample was frozen at $-20^{\circ} \mathrm{C}$ until the assay for 6-keto $\mathrm{PGF}_{1 \alpha}$ was performed. Immediately after removing the dialysis tube, a laparotomy was performed and a blood sample was drawn from the descending aorta for determination of whole blood thromboxane synthesis, as described previously (21). Thromboxane $\mathrm{B}_{2}$ levels in serum from 1-ml blood samples were measured using a specific ELISA assay. As platelets are the predominant source of thromboxane synthesis, and only contain the COX-1 isoform $(2,3)$, this assay served as an index of inhibitory effects of the test drugs on COX-1 activity. Levels of 6-keto $\mathrm{PGF}_{1 \alpha}$ in the colonic dialysates were measured using a specific ELISA, as described previously (20).

In separate experiments, in vivo colonic dialysis was performed using healthy rats, and the effects of pretreatment with diclofenac $(10 \mathrm{mg} / \mathrm{kg})$ or L745,337 $(5 \mathrm{mg} / \mathrm{kg})$ vs. vehicle were determined $(n=6$ per group).

COX mRNA determinations. Colonic COX-1 and COX-2 mRNA expression was measured using reverse transcriptase polymerase chain reaction (RT-PCR). Samples of the distal colon (full thickness) were taken from rats at 24 and $72 \mathrm{~h}, 1$ and 2 wk after intracolonic administration of saline or TNBS. Additional experiments were performed using rats $72 \mathrm{~h}$ after induction of colitis $(n=6)$ and healthy control rats $(n=6)$ in which the tissue samples were divided along the submucosa, thereby yielding a "mucosal" and a "muscularis" sample. The tissue samples were immediately frozen in a $50 \%$ (wt/ vol) guanidinium solution containing $26.4 \mathrm{mM}$ sodium citrate $(\mathrm{pH}$ 7.0), $0.528 \%$ sarcosyl, and $0.0072 \% \quad \beta$-mercaptoethanol. For each $100 \mathrm{mg}$ of tissue, $1 \mathrm{ml}$ of the guanidinium solution was used. Total RNA was isolated using the acid guanidinium isothiocyanate method, as described previously (22).

To address the problems associated with substrate competition while simultaneously monitoring multiple mRNAs within the same sample, the primer-dropping method was employed (23). The gene for glyceraldehyde 3-phosphate dehydrogenase (GAPDH) was used as an internal control (23). Briefly, $1 \mu \mathrm{g}$ of RNA from each sample was reverse transcribed at $42^{\circ}(\mathrm{C}$ using Superscript RNase H Reverse Transcriptase and the appropriate reaction mixture (containing $2 \mu \mathrm{l}$ $10 \times$ PCR buffer, $2 \mu \mathrm{l} 10 \mathrm{mM}$ dNTP stock, and $2 \mu \mathrm{l} \mathrm{N}$ random hexamer stock). The enzyme was then deactivated by heating the samples to $95^{\circ} \mathrm{C}$ for $10 \mathrm{~min}$. After the reaction, $2 \mu \mathrm{l}$ of cDNA was mixed with $2 \mu 12 \mathrm{mM}$ dNTP stock and $2 \mu \mathrm{l} 10 \times$ PCR buffer. $2 \mu \mathrm{l}$ of the upstream primer $(\sim 1 \mathrm{pmol})$ and $2 \mu \mathrm{l}$ of the downstream primer $(\sim 1$ pmol) for rat COX-1 or COX-2 were then added to each tube.

DNA amplification was carried out under the following conditions: denaturation at $94^{\circ} \mathrm{C}$ for $1 \mathrm{~min}$, annealing at $55^{\circ} \mathrm{C}$ for $30 \mathrm{~s}$, and extension at $72^{\circ}(\mathrm{C}$ for $1 \mathrm{~min}$. To ensure complete denaturation of the DNA with no background polymerase activity, Taq DNA polymerase was added to the PCR mixture during the hot start of cycle 1. Preliminary trials indicated that coamplification of COX-1 and COX-2 with GAPDH was optimal if the COX-1 gene was amplified for 29 cycles, the COX-2 gene for 30 cycles, and the GAPDH gene for 20 cycles (data not shown). Hence, the GAPDH upstream and downstream primers were added to the PCR mixture during the hot start of cycle 10 for COX-1 reactions and during the hot cycle of cycle 11 for COX-2 reactions.

After separation of the PCR products on a $2 \%$ agarose gel containing ethidium bromide, a Polaroid picture of the gel was taken under ultraviolet light. Using a densitometer and National Institutes of Health software, quantities of each product were normalized according to control levels of GAPDH, and expressed as densitometry units.

The COX-1 and COX-2 RT-PCR products were made using primers designed according to the published sequence for the rat enzymes (24-26). The COX-1 primer sequences were as follows: upstream, 5'-CCTTCTCCAACGTGAGCTACTA-3'; downstream, 5' TCCTTCTCTCCTGTGAACTCCT- $3^{\prime}$. The expected length of this
PCR product was $1,036 \mathrm{bp}$. The COX-2 primer sequences were as follows: upstream, 5'-AGACAGATCATAAGCGAGGAC-3'; downstream, 5'-CACTTGCATTGATGGTGGCTGT-3'. The expected length of this PCR product was 1,158 bp. The GAPDH RT-PCR product was made using primers described previously (23).

COX immunohistochemistry. Tissues from control $(n=3)$ and colitic $(n=3)$ rats were fixed by immersion in Zamboni's fixative overnight at $4^{\circ} \mathrm{C}$. After fixation, they were washed in PBS, ( $\left.\mathrm{pH} 7.4\right)$ and processed for indirect immunofluorescence as either wholemount preparations of longitudinal-muscle/myenteric plexus or submucosa (whole mounts), or as cryostat sections $(12 \mu \mathrm{m})$. Sections or whole mounts were incubated in primary antibodies for $48 \mathrm{~h}$ at $4^{\circ} \mathrm{C}$. Primary antibodies raised in rabbit against a peptide sequence from the human COX-1 or COX-2 enzymes (27) were used alone (1:500) or after preincubation with $100-2,000 \mathrm{ng} / \mathrm{ml}$ of recombinant human COX -1 or COX- 2 as preabsorption controls. After washing (PBS, $3 \times$ $10 \mathrm{~min}$ ), tissues were incubated for $1 \mathrm{~h}$ at room temperature with sheep anti-rabbit IgG conjugated to CY3 (1:200; Sigma Chemical Co., St. Louis, MO). Tissues were then washed again (PBS, $3 \times 10$ min) and mounted in bicarbonate-buffered glycerol ( $\mathrm{pH}$ 8.6). Tissues were viewed under epifluorescence with a microscope (Axioplan; Carl Zeiss, Inc., Thornwood, NY) and photographed using TMax 400 ASA black and white film (Eastman Kodak Co., Rochester, NY).

Statistical analysis. All data are expressed as the mean \pm SEM. Comparisons among groups of data were made using a one way analysis of variance followed by a Student-Newman-Keuls test. Rates of mortality among treatment groups were compared using the Fisher's Exact test. With all analyses, an associated probability $(P$ value $)<5 \%$ was considered significant.

Materials. Reagents for the ELISA of 6-keto $\mathrm{PGF}_{1 \alpha}$ and $\mathrm{TXB}_{2}$ were obtained from Caymen Chemical Co. Inc. (Ann Arbor, MI). Diclofenac sodium, nabumetone, naproxen, etodolac, the reagents for the MPO assay, sarcosyl and isopropanol were obtained from Sigma Chemical Co. $\beta$-Mercaptoethanol was obtained from Bio Rad Laboratories Inc. (Mississauga, ON, Canada). Sodium acetate and diethyl pyrocarbonate were obtained from BDH Chemicals Ltd. (Edmonton, $\mathrm{AB}$, Canada). Guanidinium was obtained from VWR (Edmonton, AB, Canada). PCR buffer and dNTP stock were obtained from Pharmacia LKB Biotechnology Inc. (Mississauga, ON, Canada). Sodium citrate, phenol, and superscript RNase $\mathrm{H}$ reverse transcriptase were obtained from GIBCO BRL (Gaithersburg, MD). L745,337, recom-

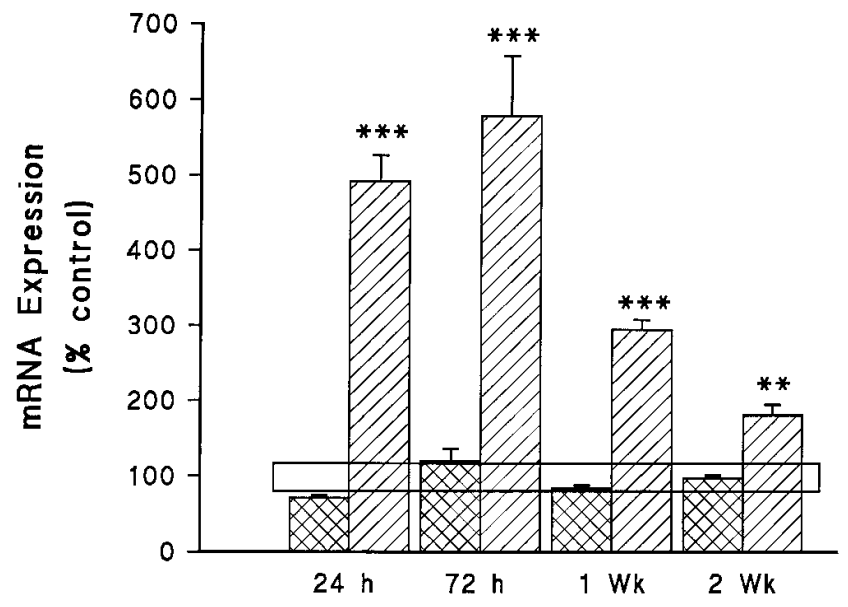

Figure 1. Expression of mRNA for COX-1 and COX-2 in the colon of rats $24 \mathrm{~h}$ to $2 \mathrm{wk}$ after induction of colitis. The results are expressed as a percentage of the expression observed in healthy control rats (the open square represents the mean \pm SEM expression in healthy controls). Each group consisted of four to six rats. $* * P<0.01$, *** $P<$ 0.001 compared with the healthy control rats killed on the same day as the colitic rats. $\mathbf{\square}, \mathrm{COX}-1 ; \square, \mathrm{COX}-2$. 

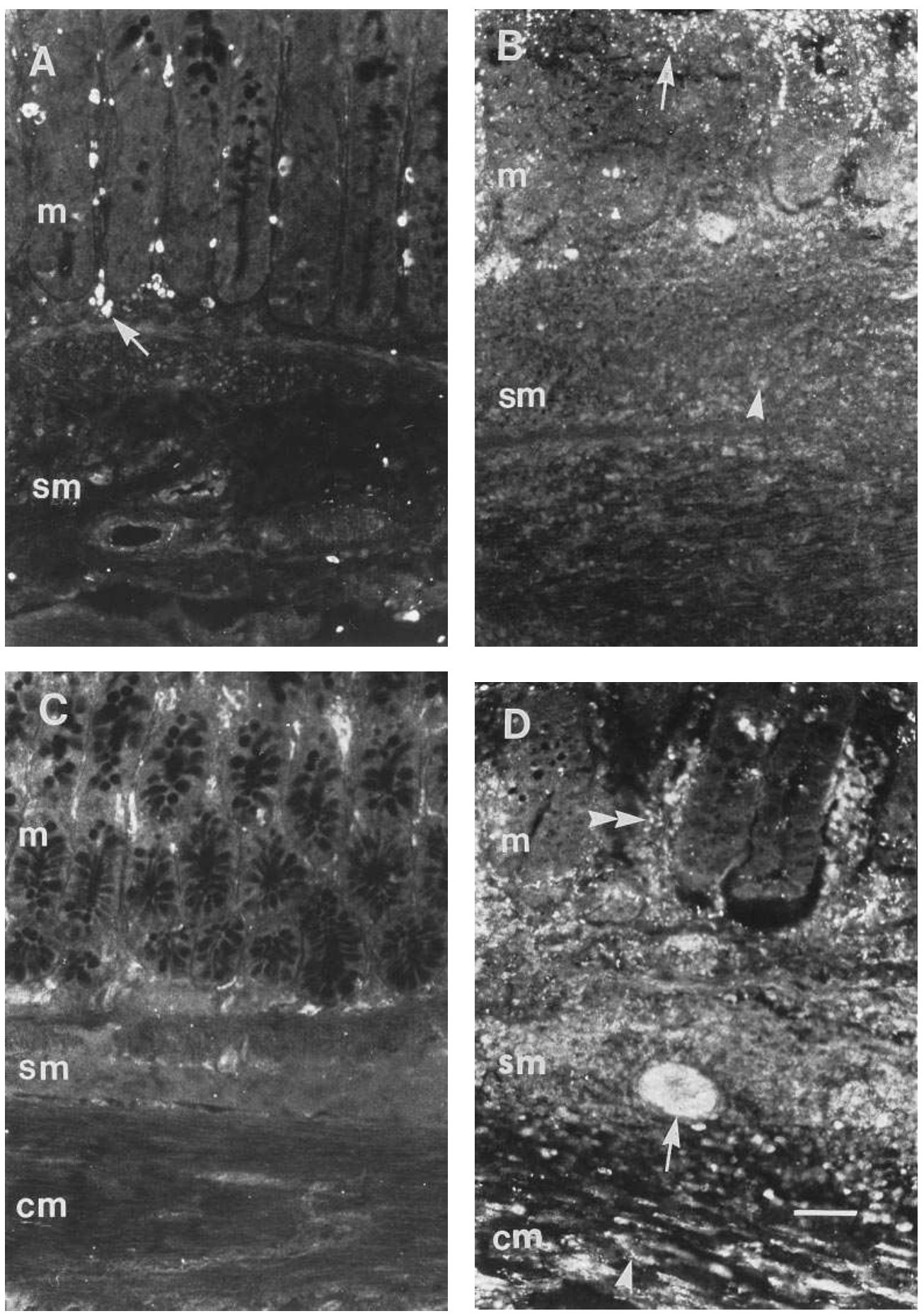

Figure 2. COX-1 ( $A$ and $B$ ) and COX-2 $(C$ and $D)$ immunoreactivity in sections from healthy ( $A$ and $C$ ) and colitic ( $B$ and $D$ ) rats. COX-1 immunoreactivity was observed in a population of cells in the lamina propria ( $a r-$ row) of the colonic mucosa $(m)$ in healthy rats $(A)$, and in bacteria (arrow) in colitic rats $(B)$. Weak COX-1 immunoreactivity was also observed in infiltrating cells (arrowhead) in the submucosa $(\mathrm{sm})$ in colitic rats. COX-2 immunoreactivity was not observed in healthy control rats $(C)$. After induction of colitis, COX-2 was expressed in the smooth muscle of the muscularis externa (arrowhead), in infiltrating cells in the submucosa $(\mathrm{sm})$, in submucosal blood vessels ( $a r$ row) and bacteria (double arrowhead) $(D) . \mathrm{cm}$, circular muscle. Scale bar: $50 \mu \mathrm{m}$.

binant human COX-1 and -2 and the antibodies directed against COX-1 and -2 were generously provided by Drs. C.C. Chan and I. Rodger of Merck-Frosst Therapeutic Research Centre (Montreal, QC, Canada). COX-1, COX-2, and GAPDH primers were synthesized by University Core DNA Services (University of Calgary, Calgary, $\mathrm{AB}, \mathrm{Canada})$.

\section{Results}

The colitis induced by TNBS has been described in detail previously $(15,20)$, and the macroscopical and histological appearance of the colitis induced in this study were similar to these previous descriptions. Briefly, transmural inflammation of the distal colon with ulceration extending to the depth of the muscularis propria was consistently observed. Granulocyte and lymphocyte infiltration was extensive, with granulocytes (primarily neutrophils) being heavily concentrated in the tissue surrounding sites of ulceration. This infiltration was evident at all time points studied ( $24 \mathrm{~h}-2$ wk post-TNBS), with the greatest infiltrate observed at the 72-h time point, corresponding to the previously reported peak in tissue myeloperoxidase activity $(15,20)$.

$C O X-1$ and $C O X-2 \mathrm{mRNA}$ expression. After induction of colitis, COX-1 mRNA expression was not significantly altered 
relative to controls at any of the time points examined ( $24 \mathrm{~h}-2$ wk post-TNBS). On the contrary, COX-2 mRNA expression was significantly elevated at all four time points examined (Fig. 1). The highest levels of expression were observed at the earlier time points ( 24 and $72 \mathrm{~h}$ ), where COX-2 mRNA expression was elevated four- to sixfold over control levels. COX-2 mRNA expression decreased thereafter.

At $72 \mathrm{~h}$ after induction of colitis, the expression of COX-2 mRNA occurred predominantly in the mucosal layer (386.9 $\pm 66.8 \%$ of control levels; $P<0.01$ ). However, expression of COX-2 mRNA in the muscularis propria was also significantly elevated above control levels $(173.1 \pm 17.5 \% ; P<$ $0.05)$.

$C O X-1$ and $C O X-2$ immunohistochemistry. As the greatest change in COX-2 mRNA expression occurred at $72 \mathrm{~h}$ after induction of colitis, immunohistochemical studies were focused at that time point. Liquid-phase preabsorption with $100-500$ $\mathrm{ng} / \mathrm{ml}$ of human recombinant COX -1 or $\mathrm{COX}-2$ completely abolished staining of resident or infiltrating cells immunoreactive for these enzymes. Muscle staining with COX-2 was virtually abolished at $500 \mathrm{ng} / \mathrm{ml}$, and completely abolished at 2,000 $\mathrm{ng} / \mathrm{ml}$. These results suggest that the localization of the en- zymes was specific and that different tissues have variable amounts of the enzymes. In no cases was staining observed in colonic epithelial cells, or enteric nerves with either antibody.

In tissues from control rats, COX-1 immunoreactivity was found only in a population of cells in the lamina propria of the colonic mucosa (Fig. 2). No staining was observed in muscle or blood vessels. The labeled cells were distributed and had a density similar to that of mucosal mast cells; however, further studies would be required to confirm these as the source of COX-1 in the normal colon. In inflamed tissues, there was some diffuse staining in the submucosa, associated with the marked infiltration of inflammatory cells (Fig. 2). There was also intense labeling in very small, punctate cells in the colonic lumen and attached to the mucosal surface. Based on their size and location, these cells appeared to be bacteria. However, subsequent studies in which RT-PCR for COX-2 was performed on samples of bacteria harvested from the colonic lumen yielded negative results, suggesting that either the immunoreactive cells were not bacteria, or that the staining of bacteria with anti-COX-2 was nonspecific.

In tissues from control rats, no specific COX-2 immunoreactivity was observed (Figs. 2 and 3). In inflamed tissues, in-
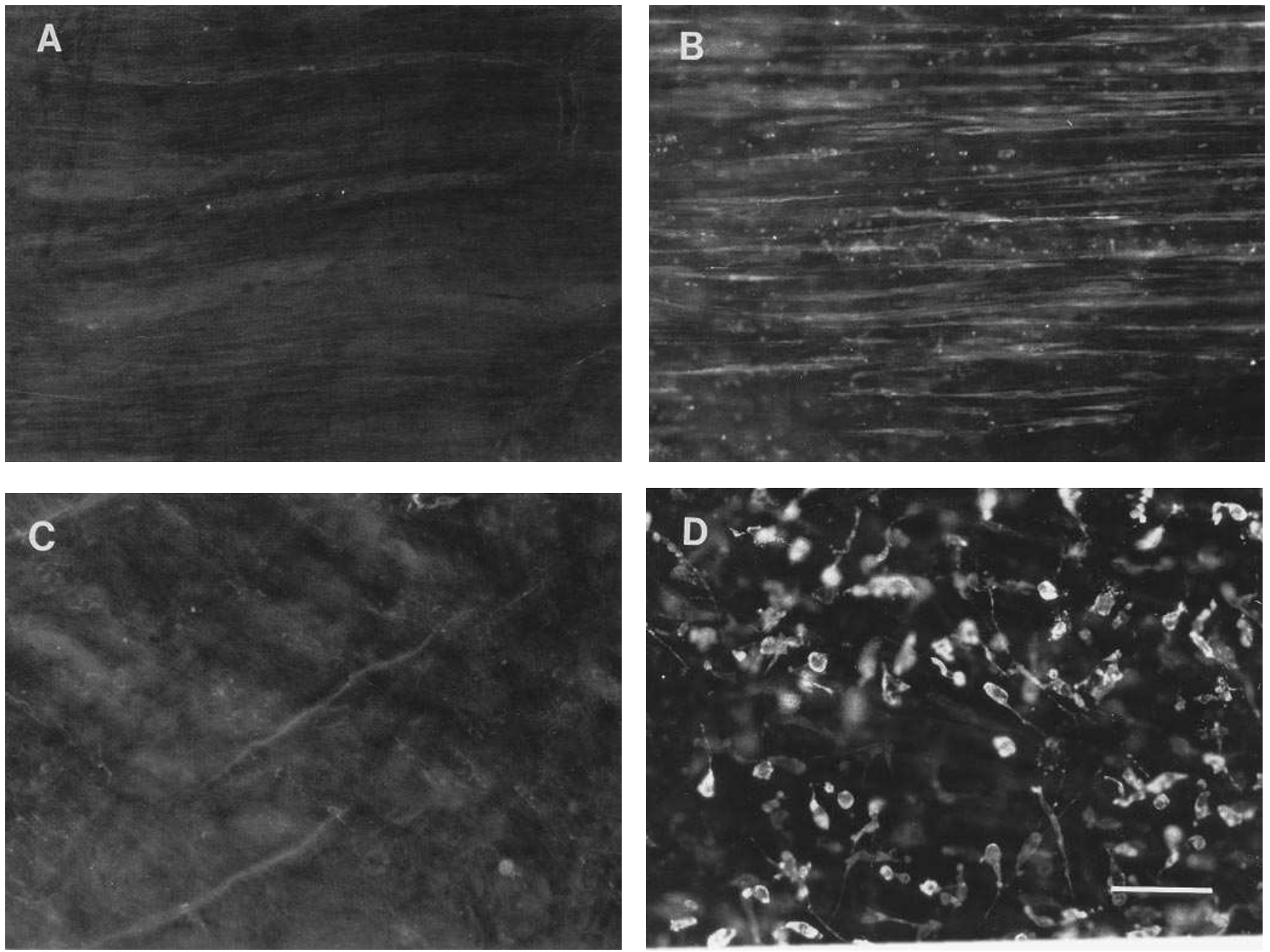

Figure 3. COX-2 immunoreactivity in whole-mount preparations from healthy ( $A$ and $C$ ) and colitic $(B$ and $D)$ rats. COX-2 immunoreactivity was not observed in control rats $(A$ and $C)$. After induction of colitis, COX-2 was expressed in smooth muscle cells $(B)$ and in infiltrating cells in the submucosa $(D)$. Scale bar: $50 \mu \mathrm{m}$. 
tense COX-2 immunoreactivity was observed in both sections and whole mounts in longitudinal and circular smooth muscle, infiltrating cells in the submucosa, blood vessels, and bacteria associated with the inflamed mucosa (Figs. 2 and 3). With respect to the blood vessels, staining was apparent in the endothelial lining as well as cellular exudates containing leukocytes (Fig. 2). The nature of the infiltrating cells in the submucosa was not fully determined. However, at least some were macrophages based on double-labeling immunohistochemistry with an antimacrophage monoclonal antibody (data not shown). Double labeling with a specific neuronal marker (protein gene product 9.5) revealed that COX-2 immunoreactivity was not found in nerves within the rat colon.

Immunohistochemical staining was also performed using tissues taken at later times after induction of colitis. At $7 \mathrm{~d}$ post-TNBS, COX-2 immunoreactivity was still evident, but at lower intensity than that seen at $3 \mathrm{~d}$. By $14 \mathrm{~d}$ after induction of colitis, staining for COX-2 was not apparent in sections or whole mounts.

Colonic prostaglandin synthesis: effects of selective $C O X-2$ inhibition. Basal colonic synthesis of 6-keto $\mathrm{PGF}_{1 \alpha}$, as measured by in vivo colonic dialysis, averaged $1.8 \pm 0.3 \mathrm{ng} / \mathrm{ml}$ in healthy control rats. Prior administration of the selective COX-2 inhibitor, L745,337 (5 mg/kg), had no significant effect on basal colonic prostaglandin synthesis $(1.7 \pm 0.7 \mathrm{ng} / \mathrm{ml})$. However, pretreatment with diclofenac $(10 \mathrm{mg} / \mathrm{kg})$ reduced basal colonic prostaglandin synthesis by $\sim 50 \%(0.9 \pm 0.2 \mathrm{ng} /$ $\mathrm{ml}, P<0.05)$.

In rats with colitis, colonic 6-keto $\mathrm{PGF}_{1 \alpha}$ synthesis was elevated $\sim 25$-fold above that observed in healthy rats (Fig. $4 A$ ). A single oral administration of diclofenac $(10 \mathrm{mg} / \mathrm{kg})$ or L745,337 $(5 \mathrm{mg} / \mathrm{kg})$ resulted in significant reductions in colonic 6-keto $\mathrm{PGF}_{1 \alpha}$ synthesis (39 and 53\%, respectively), while a lower dose of L745,337 (1 mg/kg) had no significant effect (data not shown).

Measurement of whole blood thromboxane synthesis from the same animals used in the colonic dialysis studies provided an index of COX-1 suppression. L745,337 did not significantly affect thromboxane synthesis (Fig. $4 \mathrm{~B}$ ), indicating that it did not affect COX-1 at the doses tested. In contrast, diclofenac inhibited thromboxane synthesis by $>92 \%(P<0.001)$.

Effects of COX inhibitors on colonic damage and mortality. Mortality in colitic rats treated twice daily with vehicle occurred in only 4 of 30 rats $(13 \%)$. In each case, necropsy revealed perforation of the distal colon with peritonitis. In rats treated twice daily with diclofenac, mortality was not observed over the first $6 \mathrm{~d}$ of the study, but thereafter, deaths occurred frequently (Fig. $5 A$ ). By the end of the 2-wk study period, $86 \%$ of the rats in this group had died $(P<0.0001$ compared with mortality in the vehicle-treated rats). Invariably, necropsy revealed perforation of the distal colon, peritonitis, and, in many cases, massive adhesions between the colon and other abdominal tissues. A significant increase in mortality, related to colonic perforation, was also observed in the rats treated with naproxen. Mortality in rats treated with aspirin $(20 \%)$ did not differ significantly from that observed in vehicle-treated rats.

Treatment of colitic rats with the moderately and highly selective COX-2 inhibitors also resulted in significant increases in rates of mortality. As shown in Fig. $5 \mathrm{~B}$, a majority of rats treated with nabumetone $(25 \mathrm{mg} / \mathrm{kg})$, etodolac $(10 \mathrm{mg} / \mathrm{kg})$, or $\mathrm{L} 745,337(5 \mathrm{mg} / \mathrm{kg})$ died before completion of the $14-\mathrm{d}$ study
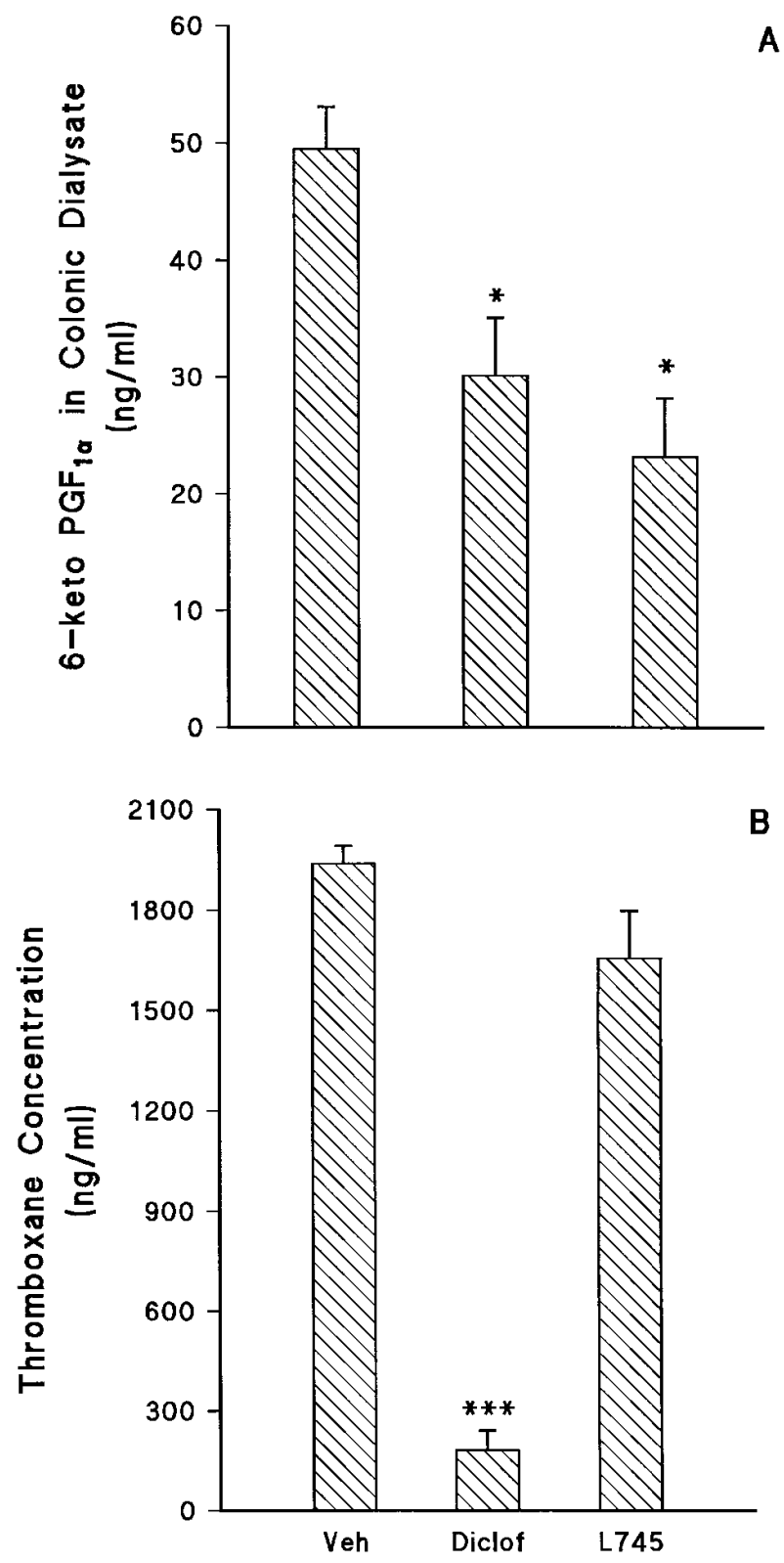

Figure 4. Effects of diclofenac and L745,337 on colonic prostaglandin synthesis $(A)$ and whole blood thromboxane synthesis $(B)$. Colonic prostaglandin synthesis was measured by in vivo colonic dialysis and measurement of 6-keto prostaglandin $\mathrm{F}_{1 \alpha}$ concentrations. Thromboxane synthesis by whole blood was measured as an index of the inhibition of COX-1 by the test drugs. These studies were performed using rats ( $n=5$ per group) $72 \mathrm{~h}$ after induction of colitis. Dialysis was performed over a 1-h period beginning $2 \mathrm{~h}$ after administration of the test drugs. Blood was taken for thromboxane measurement at the end of the dialysis period. $* P<0.05, * * * P<0.001$ compared with the vehicle-treated group.

period. With these doses of etodolac and L745,337, the rates of mortality reached $100 \%$. The lower dose of L745,337 (1 mg/kg) did not increase mortality above that seen in vehicle-treated rats ( 1 of 5 died), while in rats treated with nabumetone at 75 $\mathrm{mg} / \mathrm{kg}$ or etodolac at $50 \mathrm{mg} / \mathrm{kg}$, the rates of mortality were 47 and $100 \%$, respectively. Again, the deaths of rats in these 

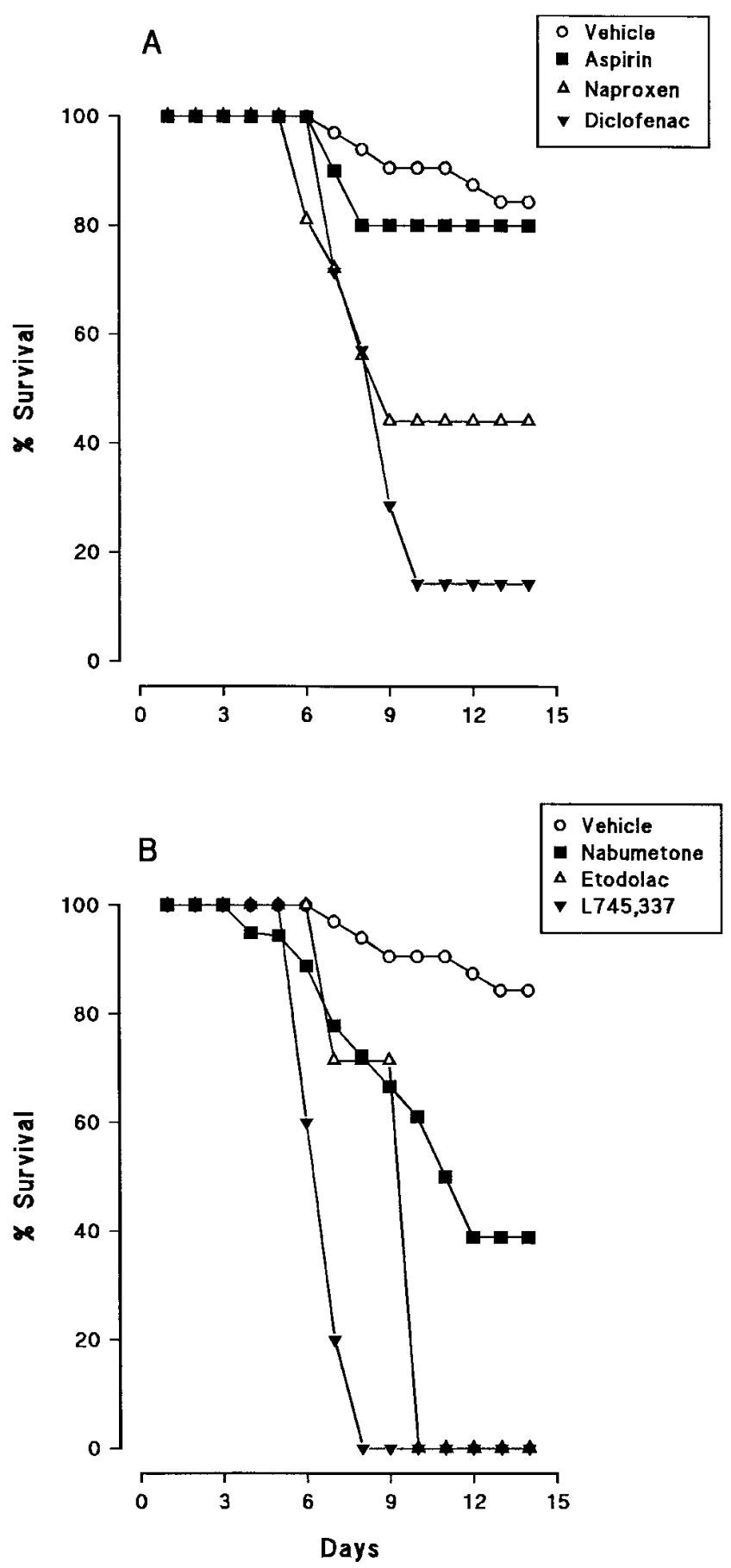

Figure 5. Survival of colitic rats ( $n \geq 10$ per group) treated twice daily for $1 \mathrm{wk}$ with standard NSAIDs $(A)$ or selective COX-2 inhibitors $(B)$. The rates of mortality were significantly greater with all test drugs except aspirin, compared with that observed with vehicle $(P<$ 0.01 ; Fisher's Exact test). Colitis was induced on day 1 . The test drugs were administered on days 1 through 7 .

groups was invariably associated with perforation of the distal colon.

The low number of animals surviving until the end of the study period precluded a comparison on the severity of colonic damage among the treatment groups. For this reason, a separate series of studies was performed in which the rats $(n=5$
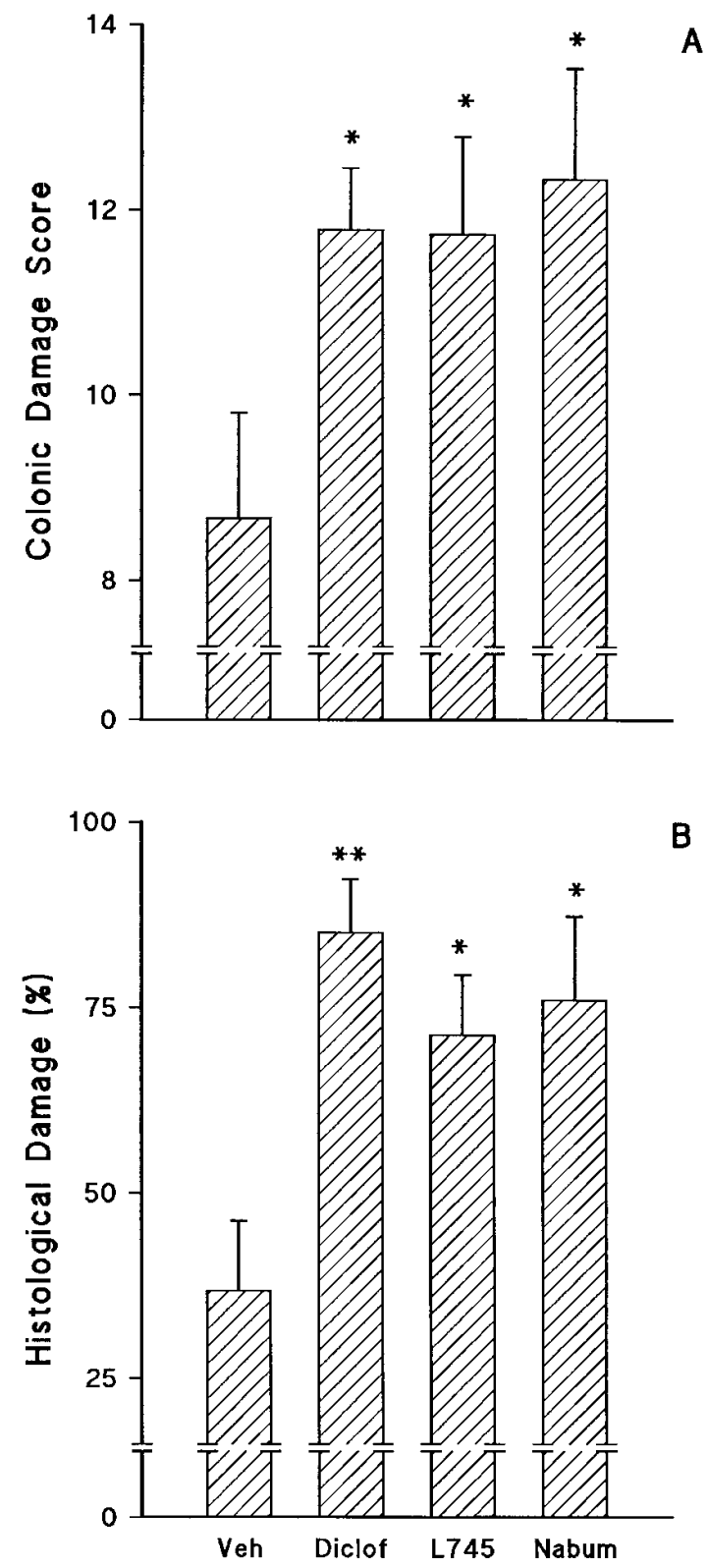

Figure 6. Effects of treatment with vehicle, diclofenac, L745,337, or nabumetone on macroscopic $(A)$ and histological $(B)$ colonic damage in rats with colitis. The test drugs were administered $3 \mathrm{~h}$ before and every $12 \mathrm{~h}$ after induction of colitis. The rats were killed $72 \mathrm{~h}$ after induction of colitis for assessment of colonic damage. Macroscopic scoring involved blind assessment of severity of damage using criteria described in detail in Table I. Histological assessment involved blind measurement of the extent of ulceration as a percentage of the total length of surface epithelium. Each bar represents the mean \pm SEM for five rats per group. ${ }^{*} P<0.05, * * P<0.01$ compared with the vehicletreated group.

per group) were killed after $3 \mathrm{~d}$ of drug administration and the colonic damage was scored (macroscopically and histologically). For these studies, only vehicle, diclofenac $(10 \mathrm{mg} / \mathrm{kg})$, L745,337 $(5 \mathrm{mg} / \mathrm{kg})$, and nabumetone $(75 \mathrm{mg} / \mathrm{kg})$ were compared. As shown in Fig. $6 \mathrm{~A}$, all three of the test drugs significantly increased the colonic damage score above that observed in vehicle-treated rats. No deaths occurred over the course of 
this study. Fig. $6 \mathrm{~B}$ summarizes the results of the histological evaluation, which demonstrated that all three test drugs significantly increased the extent of ulceration.

In addition to increasing the severity of colonic injury, the incidence of diarrhea increased from $40 \%(2 / 5)$ in the vehicletreated group to $100 \%$ in the groups treated with diclofenac, L745,337, and nabumetone. Hematocrit was significantly reduced in diclofenac-treated rats relative to vehicle-treated ( $25.8 \pm 1.6$ vs. $47.0 \pm 0.4$, respectively, $P<0.001)$, but not in the other groups (L745,337, 49.6 \pm 1.5 ; nabumetone, 51.2 \pm 1.2 ). Granulocyte infiltration into the colon (tissue MPO activity) was not significantly affected by any of the test drugs (vehicle, $16.1 \pm 2.9 \mathrm{U} / \mathrm{mg}$; diclofenac, $15.4 \pm 3.4 \mathrm{U} / \mathrm{mg}$; L745,337, 25.9 \pm 4.9 $\mathrm{U} / \mathrm{mg}$; nabumetone, $19.3 \pm 4.2 \mathrm{U} / \mathrm{mg}$ ).

\section{Discussion}

In this study, we have demonstrated that in experimental colitis there is a marked elevation of the expression of mRNA for COX-2 but not COX-1, an increase in the levels of COX-2 (but not COX-1) enzyme within the colonic tissue, and an increase in prostaglandin synthesis by the colon, which appears to be largely derived via COX-2. Furthermore, the prostaglandins derived from COX-2 appeared to play a key role in the maintenance of mucosal integrity, since administration of three drugs with moderate to high selectivity for inhibiting COX-2 significantly exacerbated the severity of colonic injury in experimental colitis. Continued twice-daily administration of these compounds for a week resulted in perforation of the colon, leading to death in a substantial portion of the animals.

While suggested to exist as long ago as 1972 (28), an inducible isoform of cyclooxygenase was only identified in 1991 (29). Since that time, a considerable amount of evidence has been generated to support the hypothesis that COX-2 is expressed at sites of inflammation and is a major contributor to the prostaglandin synthesis occurring at those sites (5-8). While COX-1 is constitutively expressed in many tissues, it can also be induced under certain conditions, including in response to interleukin-1 (30). On the other hand, COX-2 is induced in noninflammatory conditions in some tissues (e.g., cerebral cortex, endometrium, or fetal tissue) (31-33). The focus of the present study was the possibility that COX-2 expression would be elevated in the colon after induction of an inflammatory response. While there are low levels of mRNA for COX-2 detectable in the normal colon of the rat, we could not detect COX-2 protein. Moreover, COX-2 did not appear to contribute to basal prostaglandin synthesis by the colon of normal rats, since administration of the highly selective COX-2 inhibitor, $\mathrm{L} 745,337$, had no effect on prostaglandin generation in this situation. Our results are consistent with those of DuBois et al. (34) and Gustaffson-Svärd et al. (35), who showed COX-1 and COX-2 mRNA expression in the normal rat colon (the latter at low levels). Low or undetectable levels of COX-2 mRNA expression in human colon have also been reported (35-37). Interestingly, elevated expression of COX-2 in the colon has been demonstrated in human colorectal cancer and in experimental models of colonic adenocarcinoma (34-37). While there have been recent preliminary reports of elevated COX-2 mRNA expression in experimental colitis $(38,39)$ and human IBD (40), we believe that the present study represents the first report of increased COX-2 protein and COX-2-derived prostaglandin synthesis in the context of colitis.
Highly selective inhibitors of COX-1 activity in vivo are not yet available, so it is difficult to determine the precise contribution of COX-1 vs. COX-2 to prostaglandin synthesis by a tissue. However, from the data on suppression of colonic prostaglandin synthesis by diclofenac and L745,337 presented in the present study, it is possible to deduce that the majority of prostaglandins produced in animals with colitis were derived from COX-2. The highly selective COX-2 inhibitor, L745,337, had no effect on COX-1 at the dose used, as demonstrated by its failure to inhibit thromboxane synthesis. The failure of L745,337 to affect basal prostaglandin synthesis by the colon suggests that COX-1 accounted for all of this synthesis, consistent with the immunohistochemistry demonstrating no detectable COX-2 expression, along with the RT-PCR data showing only trace expression of COX-2 mRNA. The 53\% reduction by L745,337 of prostaglandin synthesis in colitic rats suggests that at least this proportion of inflammation-associated prostaglandin synthesis was derived from $\mathrm{COX}-2$. This deduction is consistent with the demonstration of marked upregulation of COX-2 protein and mRNA expression, with little or no change in COX-1 expression. It is interesting that the same dose of L745,337 produced a comparable percent reduction of carrageenan-induced paw edema in the rat, and this was attributed by the authors of that study to suppression of COX-2 by the compound (7).

The ability of moderate to highly selective COX-2 inhibitors to significantly exacerbate colonic injury in the TNBS model suggests that prostaglandins derived from COX-2 are beneficial in the setting of colonic inflammation. There is a strong body of evidence to suggest that prostaglandins do exert antiinflammatory and mucosal protective effects in experimental colitis. For example, exogenous prostaglandins can reduce the severity of colitis in the TNBS model and in other models of colitis $(20,41,42)$. Prostaglandins are capable of reducing the production of reactive oxygen metabolites (43) and a number of inflammatory mediators suggested to contribute to the pathogenesis of human IBD and experimental colitis, including leukotriene $\mathrm{B}_{4}$ and $\mathrm{TNF} \alpha(44,45)$. In a previous study using this model, we reported that the exacerbation of colonic injury by NSAIDs was not accompanied by elevated production of leukotriene $\mathrm{B}_{4}$, nor was it prevented by inhibition of leukotriene synthesis (14). While NSAIDs have been shown to elevate $\mathrm{TNF} \alpha$ release (45), the contribution of this cytokine to NSAID-induced exacerbation of colonic damage has not been examined. However, given the considerable evidence supporting a role for $\mathrm{TNF} \alpha$ in the pathogenesis of human IBD, particularly Crohn's disease $(46,47)$, this question warrants further study. Prostaglandins can also reduce leukocyte adherence to the vascular endothelium, while NSAIDs have been shown to increase such adhesive interactions in the mesenteric microcirculation (48). However, administration of standard NSAIDs or selective COX-2 inhibitors did not significantly affect the extent of mucosal granulocyte infiltration, as measured by tissue myeloperoxidase activity, so it seems unlikely that this is the underlying mechanism for exacerbation of injury by these agents.

Much of the mortality observed in this study occurred subsequent to cessation of treatment with NSAIDs or COX-2 inhibitors. This is consistent with the time frame of mortality in our previous studies of other NSAIDs $(14,18)$ and is likely related to the continued presence of the NSAID in serum for many hours or days after treatment was ceased. Also, it is pos- 
sible that suppression of prostaglandin synthesis initiated a chain of events that led to perforation of the colon and death; but once initiated, this chain of events was irreversible even though NSAID administration had been discontinued. The observation that the drugs with selectivity for COX-2 induced mortality at higher rates than was observed with standard NSAIDs (which are more selective for COX-1 than COX-2) suggests that inhibition of COX-2 may have been the underlying cause of the exacerbation of injury and the mortality. In the future, the availability of highly selective inhibitors of COX-1 may help to clarify whether or not this is the case.

Given that the inflammatory infiltrate in the TNBS model of colitis is transmural, it is not surprising that mRNA for COX-2 would be elevated in both the mucosa and the muscularis propria, nor that there would be a greater increase in the former than the latter. However, we did not anticipate so strong an expression of COX-2 protein in the muscularis propria of the inflamed colon as was observed in this study. As prostaglandins have well characterized effects on smooth muscle, it is possible that prostaglandins produced from COX-2 expressed in the muscularis contribute to the altered motility that occurs in colitis.

These results, if extendable to humans, bring into question the proposal that highly selective inhibitors of COX-2 will be "gastrointestinal sparing." While in experimental models involving healthy animals these compounds have proven to cause markedly less gastrointestinal injury than standard NSAIDs (6-8), no previous study has examined the effects of these compounds in a setting of preexisting intestinal inflammation. Until such a time as selective COX-2 inhibitors have been adequately assessed in human conditions characterized by mucosal inflammation (e.g., IBD or H. pylori-associated peptic ulcer), caution should be exercised when regarding these compounds as "gastrointestinal safe."

\section{Acknowledgments}

The authors thank Winnie Ho for her assistance in performing these studies.

This work was supported by grants from the Medical Research Council of Canada (MRC) and the Crohn's and Colitis Foundation of Canada. J.L. Wallace is an MRC Senior Scientist and an Alberta Heritage Foundation for Medical Research (AHFMR) Scientist. K.A. Sharkey is an AHFMR Senior Scholar.

\section{References}

1. Soll, A.H., W.M. Weinstein, J. Kurata, and D. McCarthy. 1991. Nonsteroidal anti-inflammatory drugs and peptic ulcer disease. Ann. Intern. Med. 114: 307-319.

2. Xie, W., D.L. Robertson, and D.L. Simmons. 1992. Mitogen-inducible prostaglandin $\mathrm{G} / \mathrm{H}$ synthase: a new target for nonsteroidal antiinflammatory drugs. Drug Dev. Res. 25:249-265.

3. Meade, E.A., W.L. Smith, and D.L. DeWitt. 1993. Differential inhibition of prostaglandin endoperoxide synthase (cyclooxygenase) isozymes by aspirin and other non-steroidal anti-inflammatory drugs. J. Biol. Chem. 268:6610-6614.

4. Mitchell, J.A., P. Akarasereenont, C. Thiemermann, R.J. Flower, and J.R. Vane. 1993. Selectivity of nonsteroidal antiinflammatory drugs as inhibitors of constitutive and inducible cyclooxygenase. Proc. Natl. Acad. Sci. USA. 90:11693-11697.

5. Vane, J.R., J.A. Mitchell, I. Appleton, A. Tomlinson, D. Bishop-Bailey, J. Croxtall, and D.A. Willoughby. 1994. Inducible isoforms of cyclooxygenase and nitric oxide synthase in inflammation. Proc. Natl. Acad. Sci. USA. 91:20462050 .

6. Masferrer, J.L., B.S. Zweifel, P.T. Manning, S.D. Hauser, K.M. Leahy, W.G. Smith, P.C. Isakson, and K. Seibert. 1994. Selective inhibition of inducible cyclooxygenase 2 in vivo is antiinflammatory and nonulcerogenic. Proc. Natl.
Acad. Sci. USA. 91:3228-3232.

7. Chan, C.C., S. Boyce, C. Brideau, A.W. Ford-Hutchinson, R. Gordon, D Guay, R.G. Hill, C.S. Li, J. Mancini, M. Penneton et al. 1995. Pharmacology of a selective cyclooxygenase-2 inhibitor, L-745,337: a novel nonsteroidal antiinflammatory agent with an ulcerogenic sparing effect in rat and nonhuman primate stomach. J. Pharmacol. Exp. Ther. 274:1531-1537.

8. Seibert, K., Y. Zhang, K. Leahy, S. Hauser, J. Masferrer, W. Perkins, L. Lee, and P. Isakson. 1994. Pharmacological and biochemical demonstration of the role of cyclooxygenase 2 in inflammation and pain. Proc. Natl. Acad. Sci. USA. 91:12013-12017.

9. Schattenkirchner, M. 1990. An updated safety profile of etodolac in several thousand patients. Eur. J. Rheumatol. Inflammation. 10:56-65.

10. Willkens, R.F. 1990. An overview of the long-term safety experience of nabumetone. Drugs. 40 (Suppl. 5):34-37.

11. Glaser, K., M.L. Seng, K. OíNeill, M. Belfast, D. Hartman, R. Carlson, A. Kreft, D. Kubrak, C.L. Hsiao, and B. Weichman. 1995. Etodolac selectively inhibits human prostaglandin G/H synthase 2 (PGHS-2) versus human PGHS-1. Eur. J. Pharmacol. 281:107-111.

12. Stadler, P., D. Armstrong, D. Margalith, E. Saraga, M. Stolte, P. Lualdi, G. Mautone, and A. Louis. 1991. Diclofenac delays healing of gastroduodenal mucosal lesions. Double-blind, placebo-controlled endoscopic study in healthy volunteers. Dig. Dis. Sci. 36:594-600.

13. Kaufmann, H.J., and H.L. Taubin. 1987. Nonsteroidal anti-inflammatory drugs activate quiescent inflammatory bowel disease. Ann. Intern. Med. 107:513-516.

14. Wallace, J.L., C.M. Keenan, D. Gale, and T.S. Shoupe. 1992. Exacerbation of experimental colitis by NSAIDs is not related to elevated leukotriene $\mathrm{B}_{4}$ synthesis. Gastroenterology. 102:18-27.

15. Morris, G.P., P.L. Beck, M.S. Herridge, W.T. Depew, M.R. Szewczyk, and J.L. Wallace. 1989. Hapten-induced model of chronic inflammation and ulceration in the rat colon. Gastroenterology. 96:795-803.

16. Melarange, R., C. Gentry, M. Durie, C. O'Connell, and P.R. Blower. 1994. Gastrointestinal irritancy, antiinflammatory activity, and prostanoid inhibition in the rat: differentiation of effects between nabumetone and etodolac. Dig. Dis. Sci. 39:601-608.

17. Wallace, J.L., B. Reuter, C. Cicala, W. McKnight, M. Grisham, and G. Cirino. 1994. A diclofenac derivative without ulcerogenic properties. Eur. J. Pharmacol. 257:249-255.

18. Reuter, B.K., G. Cirino, and J.L. Wallace. 1994. Markedly reduced intestinal toxicity of a diclofenac derivative. Life Sci. 55:PL1-PL8.

19. Elliott, S.N., W. McKnight, G. Cirino, and J.L. Wallace. 1995. A nitric oxide-releasing nonsteroidal anti-inflammatory drug accelerates gastric ulcer healing in rats. Gastroenterology. 109:524-530.

20. Wallace, J.L., and C.M. Keenan. 1990. An orally active inhibitor of leukotriene synthesis accelerates healing in a rat model of colitis. Am. J. Physiol. 258:G527-G534.

21. Wallace, J.L., W. McKnight, P. Del Soldato, A.R. Baydoun, G. Cirino. 1995. Anti-thrombotic effects of a nitric oxide-releasing, gastric-sparing aspirin derivative. J. Clin. Invest. 96:2711-2718.

22. Chomczynski, P., and N. Sacchi. 1987. Single-step method of RNA isolation by acid guanidinium thiocyanate-phenol-chloroform extraction. Anal. Biochem. 162:156-159.

23. Wong, H., W.D. Anderson, T. Cheng, and K.T. Riabowol. 1994. Monitoring mRNA expression by polymerase chain reaction: the "primer-dropping" method. Anal. Biochem. 223:251-258.

24. Feng, L., W. Sun, Y. Xia, W.W. Tang, P. Chanmugam, E. Soyoola, C.B. Wilson, and D. Hwang. 1993. Cloning two isoforms of rat cyclooxygenase: differential regulation of their expression. Arch. Biochem. Biophys. 307:361-368.

25. Kennedy, B.P., C.C. Chan, S.A. Culp, and W.A. Cromlish. 1993. Cloning and expression of rat prostaglandin endoperoxide synthase (cyclooxygenase)-2 cDNA. Biochem. Biophys. Res. Commun. 197:494-500.

26. O'Banion, M.K., V.D. Winn, and D.A. Young. 1992. cDNA cloning and functional activity of a glucocorticoid-regulated inflammatory cyclooxygenase. Proc. Natl. Acad. Sci. USA. 89:4888-4892.

27. Kargman, S.L., G.P. O’Neill, P.J. Vickers, J.F. Evans, J.A. Mancini, and S. Jothy. 1995. Expression of prostaglandin G/H synthase-1 and -2 protein in human colon cancer. Cancer Res. 55:2556-2559.

28. Flower, R.J., and J.R. Vane. 1972. Inhibition of prostaglandin synthetase in brain explains the anti-pyretic activity of paracetamol (4-acetamidephenol). Nature (Lond.). 120:412-411.

29. Xie, W., J.G. Chipman, D.L. Robertson, R.L. Erikson, and D.L. Simmons. 1991. Expression of a mitogen-responsive gene encoding prostaglandin synthase is regulated by mRNA splicing. Proc. Natl. Acad. Sci. 88:2692-2696.

30. Wu, K.K., R. Sanduja, T. Ah-Lim, B. Ferhanoglu, and D.S. LooseMitchell. 1991. Aspirin inhibits interleukin 1-induced prostaglandin H synthase expression in cultured endothelial cells. Proc. Natl. Acad. Sci. USA. 88:23842387.

31. Adams, J., Y. Collaco-Moraes, and J. De Belleroche. 1996. Cyclooxygenase-2 induction in cerebral cortex: an intracellular response to synaptic excitation. J. Neurochem. 66:6-13.

32. Shoda, T., K. Hatanaka, M. Saito, M. Majima, M. Ogino, Y. Harada, M. Nishijima, M. Katori, and S. Yamamoto. 1995. Induction of cyclooxygenase 
type-2 (COX-2) in rat endometrium at the peak of serum estradiol during the estrus cycle. Jpn. J. Pharmacol. 69:289-291.

33. Slater, D.M., L.C. Berger, R. Newton, G.E. Moore, and P.R. Bennett. 1995. Expression of cyclooxygenase types 1 and 2 in human fetal membranes at term. Am. J. Obstet. Gynecol. 172:77-82.

34. DuBois, R.N., A. Radhika, B.S. Reddy, and A.J. Entingh. 1996. Increased cyclooxygenase-2 levels in carcinogen-induced rat colonic tumors. Gastroenterology. 110:1259-1262.

35. Gustafson-Svärd, C., I. Lilja, O. Hallböök, and R. Sjödahl. 1996. Cyclooxygenase- 1 and cyclooxygenase- 2 gene expression in human colorectal adenocarcinomas and in azoxymethane induced colonic tumours in rats. Gut. 38: 79-84.

36. Eberhart, C.E., R.J. Coffey, A. Radhika, F.M. Giardiello, S. Ferrenbach, and R.N. DuBois. 1994. Up-regulation of cyclooxygenase 2 gene expression in human colorectal adenomas and adenocarcinomas. Gastroenterology. 107:1183-1188.

37. Sano, H., Y. Kawahto, R.L. Wilder, A. Hashiramot, S. Mukai, K. Asai, S. Kimura, H. Kato, M. Kondo, and T. Hla. 1995. Expression of cyclooxygenase-1 and -2 in human colorectal cancer. Cancer Res. 55:3785-3789.

38. Chang, A.D., K.S. Ramanujam, and K.T. Wilson. 1996. Co-expression of inducible nitric oxide synthase (iNOS), cyclooxygenase (COX-2), and TGF- $\beta$ in rat models of colitis. Gastroenterology. 110:A881. (Abstr.)

39. Tessner, T., S.M. Cohn, and W.F. Stenson. Prostaglandins enhance epithelial regeneration in dextran sodium sulfate induced colitis. Gastroenterology. 110:A1027. (Abstr.)

40. Fu, S., K.S. Ramanujam, S.J. Meltzer, and K.T. Wilson. 1996. Inducible nitric oxide synthase (iNOS) and cyclooxygenase (COX-2) expression in ulcerative colitis and Crohn's disease. Gastroenterology. 110:A910. (Abstr.)
41. Allgayer, H., K. Deschryver, and W.F. Stenson. 1989. Treatment with $16,16^{\prime}$-dimethyl prostaglandin $\mathrm{E}_{2}$ before and after induction of colitis with trinitrobenzenesulfonic acid in rats decreases inflammation. Gastroenterology. 96: 1290-1300.

42. Fedorak, R.N., L.R. Empey, C. MacArthur, and L.D. Jewell. 1990. Misoprostol provides a colonic mucosal protective effect during acetic acid-induced colitis in rats. Gastroenterology. 98:615-625.

43. Wong, K., and F. Freund. 1981. Inhibition of $n$-formylmethionyl-leucylphenylalanine induced respiratory burst in human neutrophils by adrenergic agonists and prostaglandins of the E series. Can. J. Physiol. Pharmacol. 59:915920.

44. Ham, E.A., D.D. Soderman, M.E. Zanetti, H.W. Dougherty, E. McCauley, and F.A. Kuehl. 1983. Inhibition by prostaglandins of leukotriene $\mathrm{B}_{4} \mathrm{re}-$ lease from activated neutrophils. Proc. Natl. Acad. Sci. USA. 80:4349-4353.

45. Kunkel, S.L., R.C. Wiggins, S.W. Chensue, and J. Larrick. 1986. Regulation of macrophage tumor necrosis factor production by prostaglandin $\mathrm{E}_{2}$. Biochem. Biophys. Res. Commun. 137:404-410.

46. Murch, S.H., V.A. Lamkin, M.O. Savage, J.A. Walker-Smith, and T.T. MacDonald. 1991. Serum concentrations of tumour necrosis factor $\alpha$ in childhood chronic inflammatory bowel disease. Gut. 32:913-917.

47. Van Dullemen, H.M., S.J.H. Van Deventer, D.W. Hommes, H.A. Bijl, J. Jansen, G.N.J. Tytgat, and J. Woody. 1995. Treatment of Crohn's disease with anti-tumor necrosis factor chimeric monoclonal antibody (cA2). Gastroenterology. 109:129-135.

48. Asako, H., P. Kubes, J.L. Wallace, R.E. Wolf, and D.N. Granger. 1992. Modulation of leukocyte adhesion in rat mesenteric venules by aspirin and salicylate. Gastroenterology. 103:146-152. 